University of Wollongong

Research Online

Faculty of Social Sciences - Papers (Archive) Faculty of Arts, Social Sciences \& Humanities

$1-1-2019$

Raising retention rates towards achieving vocational and career aspirations in Pacific communities

Jioji Ravulo

University of Wollongong, jioji@uow.edu.au

Follow this and additional works at: https://ro.uow.edu.au/sspapers

Part of the Education Commons, and the Social and Behavioral Sciences Commons

Research Online is the open access institutional repository for the University of Wollongong. For further information contact the UOW Library: research-pubs@uow.edu.au 


\title{
Raising retention rates towards achieving vocational and career aspirations in Pacific communities
}

\author{
Abstract \\ There is a need for culturally relevant and appropriate retention pro- grams within a climate of ever- \\ increasing neo-liberalism that is seeking to change the very nature and underlying rationale of higher \\ education. This article is posited alongside the reflections of past and current university students, who \\ highlight various socio-economic and socio- cultural pressures which affect their ability to maintain \\ engagement within tertiary institutions in which they strive to study. Pressures include the neo-liberal \\ ideology of unfettered individualism within a higher education setting, which seeks to make the university \\ a competitive producer of 'consumers' rather than life-long learners who serve and benefit their families \\ and wider communities through knowledge creation and critical application. The article also highlights \\ key factors that may assist in the retention of students from Pacific communities in Australia. This \\ includes the need to create a collective voice, the ability to have staff who exercise culturally appropriate \\ support and under- standing, opportunities to develop greater sense of belonging and connection to \\ University spaces that create an engagement within a cultural context, support to manage conflicting \\ expectations and priorities, ability to inspire and effect change in others through maintaining study \\ commitments, and the need to work to still support educational costs and family.
}

\section{Keywords}

pacific, towards, achieving, vocational, career, communities, raising, retention, aspirations, rates

\section{Disciplines}

Education | Social and Behavioral Sciences

\section{Publication Details}

Ravulo, J. (2019). Raising retention rates towards achieving vocational and career aspirations in Pacific communities. International Journal of Lifelong Education, 38 (2), 214-231. 


\title{
INTERNATIONAL JOURNAL OF LIFELONG EDUCATION
}

\section{Raising retention rates towards achieving vocational and career aspirations in Pacific communities}

\author{
Author \\ Jioji Ravulo \\ Associate Professor (Social Work) - Faculty of Social Sciences \\ UNIVERSITY OF WOLLONGONG \\ jioji@uow.edu.au
}

\begin{abstract}
There is a need for culturally relevant and appropriate retention programs within a climate of ever-increasing neo-liberalism that is seeking to change the very nature and underlying rationale of higher education. This article is posited alongside the reflections of past and current university students, who highlight various socio-economic and socio-cultural pressures which affect their ability to maintain engagement within tertiary institutions in which they strive to study. Pressures include the neoliberal ideology of unfettered individualism within a higher education setting, which seeks to make university a competitive producer of 'consumers' rather than life-long learners who serve and benefit their families and wider communities through knowledge creation and critical application. The article also highlights key factors that may assist in the retention of students from Pacific communities in Australia. This includes the need to create a collective voice, the ability to have staff who exercise culturally appropriate support and understanding, opportunities to develop greater sense of belonging and connection to University spaces that create an engagement within a
\end{abstract}


cultural context, support to manage conflicting expectations and priorities, ability to inspire and effect change in others through maintaining study commitments, and the need to work to still support educational costs and family.

\section{Keywords}

Pacific communities, Higher Education, Widening Participation

\section{Introduction}

Pasifika Achievement To Higher Education (PATHE) strives to develop aspirations towards further education \& training in Pacific communities within the greater western Sydney region. PATHE promotes options for Pasifika people to develop and gain new skills and new knowledge, leading to positive attitudes towards lifelong learning and subsequent vocational and career opportunities. Established in 2012, and facilitated by the Office of Widening Participation and the School of Social Sciences and Psychology at Western Sydney University, PATHE operates across three key components: student support, outreach activities and innovative community projects. These components are manifested through weekly support meetings for current PATHE university students, outreach programs in more than 80 primary and high schools within the region, and cultural events that celebrate the wide range of Pacific cultures that are present within the group, including those of Samoa, Tonga, the Cook Islands, and Fiji. All three components seek to encourage Pacific students' access to higher education, and their consequent retention, progression, completion and transition into employment in their field of study. More so, the program promotes scope to provoke opportunities for social inclusion and mobility, as the Pacific diaspora in Australia 
has been previously challenged by issues of marginalization due to various welfare and social needs (Ravulo, 2015, 2016).

This article discusses the presence of PATHE as an initiative in light of the practices and philosophical underpinnings of widening participation in general, especially within a climate of ever-increasing neo-liberalism that is seeking to change the very nature and underlying rationale of higher education. This is posited alongside the reflections of past and current university students involved in services provided by PATHE, who highlight the benefits of the program in light of these socio-economic pressures which are affecting the tertiary institutions in which they strive to study. In essence, the research outlined in this article combines viewpoints from Pacific young people and their families in striving to gain a better insight into the variables that impact on retention in higher education; especially in the context of intercultural perspectives. These variables include the neoliberal ideology of unfettered individualism within a higher education setting, which seeks to make university a competitive producer of 'consumers' rather than life-long learners who serve and benefit their families and wider communities through knowledge. I argue that the PATHE initiative challenges these neo-liberal paradigms through cultural understandings and attitudes towards education that are pertinent to the success of such an initiative for staff and students.

\section{Widening participation agendas}

Widening Participation is a relatively new pursuit within the higher education setting (Sellar \& Storan, 2013), and the measures of evaluating the effectiveness of its programs are still being articulated. Thus far, there is an understanding that one of its aims is to increase students' access to entry into higher education (Bowles, Fisher, McPhail, Rosenstreich, \& Dobson, 2014; Gale \& Parker, 2012) especially those from 'underrepresented' backgrounds, 
be they social or cultural (Bibbings, 2006; Reed, King, \& Whiteford, 2015; Sellar \& Storan, 2013). The position of first-in-family students accessing higher education has also been explored, and it has been argued that they are inherently disadvantaged compared to students who are not first-in-family to attend university, as the former may not possess the cultural habitus that the latter received from their predecessors (O'Shea, 2016a; Redmond, 2006).

Other measures through which these programs evaluate success have also been considered. Sellar \& Storan (2013) highlight how success is measured by a recognised change "resulting in a more 'confident' disposition" (p.51), where "affects are defined as somatic perceptions of changes in one's capacities for interaction in a given context" (ibid, citing Deleuze (1988) and Gatens \& Lloyd (1999). These measures, while helpful for individual students' attitudes towards their studies, do not have a strong causality with their progression (Sellar \& Storan, 2013). As such, the objectives of such programs are "to foster subjective dispositions such as motivation or enthusiasm" that are seen to increase students' engagement and progression within their studies (ibid). Reed, King, \& Whiteford (2015) also mention "increased capacity, increased confidence and sense of belonging, increased motivation and increased social capital" as features of successful widening participation programs, which further lead to "raised self-awareness, informed decision marking and an enhanced study experience" within higher education settings (p.386).

Gale \& Parker (2012) define student transition as "change navigated by students in their movement within and through formal education" (p.734), where the purpose of widening participation programs is to encourage students' ability to foster one's “capability to navigate change" (p.736). As a result of this ability to navigate change, it is believed that students are then able to access required information, carry on to course completion, and eventually "benefit from and, post-completion, transform economic goods and social institutions" (ibid), 
which ties into neo-liberal perspectives on an educated populace stimulating economic prosperity (Olssen \& Peters, 2005).

\section{Transition as a form of assimilation rather than collaboration}

This sense of transition is, however, "set by others" (Quinn, 2010, p. 119), and therefore seeks to draw in students who "fit" the given institution and its culture (ibid, citing Thomas, 2002, p. 427). It is rarely acknowledged that these processes of 'transition' have a language and culture of their own, and this forms the basis of qualifications being awarded to students - it is not a neutral process (ibid, citing Thomas, 2002):

Educational institutions are able to determine what values, language and knowledge are regarded as legitimate, and therefore ascribe success and award qualifications on this basis. Consequently, pedagogy is not an instrument of teaching, so much as of socialization and reinforcing status...individuals who are inculcated in the dominant culture are the most likely to succeed, while other students are penalized (Thomas, 2002, p. 431, emphasis added by Gale \& Parker, 2012, p. 741).

They go on to argue that there are three modes of transition: transition as induction, or the transition from high school to higher education; transition as development, where the person's sense of self develops as a result of higher education engagement, and transition as becoming, that is, becoming a life-long learner, where the institution initiates a sense of learning that remains with the individual for life (ibid). The first two modes imply "that assimilation and integration into university culture is the preferred method for student engagement and success" (p.746), with little to no space to affirm students' unique sense of cultural capital that are inherently a part of their identity. This latter form of student engagement seeks to create spaces that are collaborative and inclusive, where sharing is 
encouraged, thereby stimulating student interest through activities that are relevant to them as individuals. Such a perspective also seeks to foster students' sense of the professionals they are yet to become, and be culturally relevant and competent through learning styles that teach more than only academic content (whole-of-life learning) (p.748).

The pressure to assimilate to a particular culture that is present within universities and other institutions of higher learning often creates what Redmond (2006) calls "“outcasts on the inside': formally accepted by the university without ever acquiring, still less embodying, the traditional social and cultural advantages bestowed by HE" (ibid, p.119). This results in the reinforcement rather than transformation of an "already disadvantaged educational habitus" (ibid, p.119). As such, social inequalities are perpetuated due to the often-unrecognised culture of the institution (ibid, p.121), and the subtle though very real influence it has on determining students' progression to completion and transition.

Reed et al. (2015) also argues that government's attempts to throw money at institutions' widening participation programs does little to address the "growing evidence of cultural and social barriers" present within these programs (p.385). The educational providers' agendas, rather than those of community members, stipulate the conditions by which access to higher education can be granted. This, in turn, perpetuates the culture of the institution rather than actively seeking equity for those from first-in-family or "traditionally underrepresented backgrounds" (ibid). Excellence and equity are therefore perceived to be somewhat mutually exclusive within higher education institutions (ibid). 


\section{Higher education and the impacts of neo-liberalism}

It has been recognised that higher education within democracies have "three benign purposes: for personal growth, for an educated citizenry, and for producing wealth and services" (Ashwin \& McLean, 2005, p. 379). The rise of "new managerialism, wherein the values of the market are encroaching upon higher education through a 'technical-rational approach' focuses on the 'utility' of education as that which 'works' to increase competitiveness and entrepreneurialism as a means of economic stimulation" (ibid). Again, this approach favours those who possess a stronger socio-cultural capital that is aligned with the institution's way of thinking - typically those from non-underrepresented backgrounds. "Good learning", then, becomes synonymous with Western post-enlightenment ways of learning, which inherently deters "certain types of students" (ibid, p.4) due to different epistemological and ontological ways of being and learning. This is in direct contrast to what education ought to be: "an essential part of being human", where learning is seeing the world "as a reality in process" (Freire 1996, cited in ibid, p.6), and a "reality that can be experienced in different ways" (Marton and Booth in ibid). Freire goes so far as to state that

\footnotetext{
When [students] lack a critical understanding of their reality, apprehending it in fragments which they do not perceive as interacting constituents elements of the whole, they cannot truly know that reality (Freire, 1996, p. 85), in Ashwin \& McLean, 2005, p. 383.
}

Could it be, then, that the tenants of neoliberalism actually hinder students' ability to understand the reality around them, as they are generally unaware of its pressures and presence within higher education? Freire, discussing the notion of educational (and sociocultural) 'imposition' from teachers to students, highlights this issue:

I think what constitutes an imposition is to engage with the oppressed educationally without providing them with the critical tools to understand their world... By not engaging the 
oppressed critically so they can understand the veiled ideology that continually dehumanizes them, the educator is in complicity with the oppressor. To do so is to be indifferent towards the plight of the oppressed who have been violated in terms of their capacity to opt and to decide (Freire \& Macedo, 1995, pp. 388-389).

Imposition is further understood to when "one wilfully refuses to present alternatives and multiple points of reference" (ibid, p.390). This sense of imposition extends to how widening participation programs use titles such as 'underrepresented', 'minorities' and other labels, as the "so-called minorities actually constitute the majority, while the oppressors generally represent the dominant ideology of a minority" (ibid, p.398).

Within the higher education context, this dominant/minority dichotomy often takes the form of cultural capital, where first-in-family students are considered more 'at risk' compared to those that have family members that have attended university before them, and the reality of "mastering the college role" within their institutions (O'Shea, 2016a). Such students are "represented as simply 'coping' and collectively have a lower sense of belonging within the institution" (ibid), which can, in turn, lead to students choosing to "study less prestigious subjects at less prestigious universities" (Spiegler and Bednarek 2013, p. 324 in ibid n.p). Bourdieu, writing in 1986, identified the forms of cultural capital that are developed in higher education as "tangible goods such as books and pictures, institutionalised as academic credentials or awards, and the embodied form which is characterised by 'long-lasting dispositions"' (cited in ibid, p5, n.p.). When students come from backgrounds that do not necessarily garner these particular forms of cultural capital - again, those that typically come from non-underrepresented backgrounds - they arrive at higher education institutions without the knowledge of these "rules of the game", and its "hidden curriculum" (ibid). Sometimes this lack of understanding can have a demoralising effect on students, even to the point of 
leaving higher education. It is imperative that learning institutions are constantly aware of students' and staff “attitudes to underrepresented groups" (Bibbings, 2006, p. 83).

\section{Profiteering rather than knowledge creation and collective outcomes}

Neoliberalism's major impact on higher education, as stated above, is reforming the purpose of university, namely the pursuit of knowledge and its development being transformed into the economic viability of education's 'utility'. In turn, this makes each student a competitor with their peers, so that they effectively become "an enterprising and competitive entrepreneur" (Olssen \& Peters, 2005, p. 315). These attitudes promote a Western ideological frame upon all students, irrespective of their cultural and other values which they may find challenged by the overly "dominant model of globalization and the emergent form of knowledge capitalism on which it is based" (ibid, p.330). Educational support models that seek to encourage specifically cultural or other ways of interpreting the world therefore challenge this value system, and can encourage new 'realities' through shared experience to emerge, potentially stimulating "a profound rethinking of education as emerging forms of knowledge capital, involving knowledge creation, acquisition, transmission and organization" (ibid, p.331). New understandings of education (which are, in fact, old) see education as a "public good" (Giroux, 2002, p. 432) where students gain a public voice that recognises their power "as individuals and social agents" rather than simply seeking the "fulfilment of individual needs" (ibid).

The pressures of the neoliberal agenda urge universities to inject a considerable amount of their funding into courses that, unsurprisingly, result in high student numbers - otherwise known as profit - at the expense of less profitable ones, resulting in these programs being "marginalized, underfunded, or eliminated" (Giroux, 2002, p. 434). The subjects that are 
typically done away with in light of this educational militancy are those that tend to provoke change within society generally: "critical theory, literature, feminism, ethics, environmentalism, postcolonialism, philosophy, and sociology" (ibid). At best, such courses are "technicized because their role in the market [and] will be judged as ornamental" (p.434). As a result, students become "consumers" of programs rather than seekers of knowledge (ibid, p.446). Giroux (2010) aptly summarises how the neoliberal agenda is impinging upon the very foundations of what university education is becoming:

It places an emphasis on winning at all costs, a ruthless competitiveness, hedonism, the cult of individualism, and a subject largely constructed within a market-driven rationality that abstracts economics and markets from ethical considerations. Within this pedagogy, compassion is a weakness, and moral responsibility is scorned because it places human needs over market considerations. (p.185)

This attitude is in keeping with the hyper-neoliberalism experienced in, for example, in dictatorial Chile from 1973 to 1990, where "traditional universities were [considered] a source of dissent, their power and resources needed to be undercut and confronted with a new private sector" (Pitton, 2007, p. 259). Is this treatment of the university system something that Australian institutions aspire to? This treatment of education is a paradox of living within a democracy: "neoliberal practices [highlight] their inconsistency with the liberal democracies' concerns for equity, solidarity and social justice" (p.264).

\section{Retention, Progression and Completion in Higher Education}

In light of these realities being present within a higher education setting, several reasons have been identified for why students leave their studies. Bowles et al. (2014, p. 213) highlight several factors: 
(1) Intention (desire to complete)

(2) Institutional fit or commitment (comfortable in institutional climate)

(3) Psychological processes and key attitudes (self-perception of satisfaction and confidence),

(4) Academics (challenging courses),

(5) Social factors (quality of social interactions at institution)

(6) Bureaucratic factors (the way formal exchanges are handled)

(7) External environ- mental factors (forces beyond student's control)

(8) Student's background (goal, class rank, parent's education, economic status) and

(9) Money and finances.

It has also been identified that students from 'minority groups' have a higher chance of discontinuing (ibid). A need to work long hours is another factor associated with attrition (McMillan, 2005 cited in ibid, p.214), alongside being underprepared for universities that struggle to provide adequate resourcing. This lack of preparedness could be influenced by the lack of cultural capital that "non-traditional background" students encounter (ibid).

Bowles et al. (2014) identified three areas that encouraged a "sense of belonging" for higher education students, namely "study", "effort" and "culture" (p.219). Students felt that these elements of their study experience are "endogenous", or "derived from within the students themselves" (ibid, p.219). Other forms of assistance, such orientation, web-based help, and social events are "exogenous", that is, "derived external to students" (ibid). Their data showed that a mixture of student "effort" (endogenous) and the certain programs offered by the institution (exogenous) were the most influential factors in student retention (ibid). "Feelings of belonging and value" were "expressed through the measure Culture, [and] were 
positively correlated to a moderate level with the efforts students made...[whereas] exogenous measures such as Orientation, web support through Learning@Uni and Facilities were also correlated to a reasonably high degree with study" (ibid). These two areas of endogenous and exogenous factors are those that should be considered as "enablers of transition" by universities (ibid, p.222).

The role of the neoliberal agenda, when placed alongside the goals of widening participation, can often appear to be at odds with one another, as one focuses on creating an increasingly competitive atmosphere in higher education, whereas the other seeks to draw in those from 'non-traditional backgrounds' to these institutions. The remainder of this document will consider how the Pasifika Achievement To Higher Education (PATHE) initiative seeks to resist neoliberalist pressures whilst simultaneously innovating the way in which widening participation programmes engage with students and communities to foster a greater sense of inclusion within the higher education environment.

\section{Pasifika Achievement To Higher Education (PATHE) program}

The Pacific diaspora in Australia are an emerging ethnic group, with migration from across the South Pacific Islands generally undertaken to seek education and employment opportunities. Over the last 3 decades, certain trends have been cited, including the over representation of Pacific young people in youth offending (Ravulo, 2016). As a result, Pacific communities have started to appear as its own equity group across a variety of Higher Education Participation and Partnerships Program (HEPPP) funded initiatives nationally (Curtin University, 2013; Fa'avale, O’Brien, Green, \& McLaughlin, 2016; Peacock, 2014; Tualaulelei \& Kavanagh, 2015). The PATHE program was developed to assist by increasing 
the involvement of Pacific young people in further education and training, in turn bolstering the development of cultural capital, and its influence on social mobility.

The initiative offers three tiers of engagement and support for prospective and current Pasifika university students within a higher education context: student support, school outreach, and community events, to be described below. Student support comprises of weekly support meetings that attend to the academic, social and pastoral care needs of students, and often feature Pacific guest speakers from professional backgrounds. Their talks often motivate students to remain determined to complete their studies, and provide inspiration for further learning. These meetings provide the backbone of support within the PATHE program, and are for two hours each week on a designated day across four Western Sydney campuses. One PATHE Project Officer attends two meetings each week, and their facilitation are a crucial aspect of ongoing support for PATHE students. They provide a sense of consistent encouragement for retention and progression for students involved.

Other activities include PATHE students' participation in workshops, where they engage with local high schools to encourage Pacific youth to explore the opportunities available to them through higher education. Further still, PATHE hosts community event evenings on campus such as Bring The Family To Uni that welcomes and exposes parents and family members to the realities of higher education, with cultural performances and testimonies from student leaders about their experiences in higher education. Check It Out Campus Tours are carried out on Western Sydney campuses for senior high school students, again to expose them to university and open up their minds to the possibility of higher education. PATHE student ambassadors who are selected as paid staff within the program from the group of PATHE students who participated across the initiative assist in implementing various facets across the community. 
Pride in Pasifika culture, alongside creating a space for cultural understandings of what it means to be a Pacific student in a higher education setting, are areas that PATHE esteem as valuable to contributing towards students' socio-cultural capital and personal development, even if these elements of one's identity are typically not seen to be commercially significant to neoliberal agendas as discussed in the literature above.

\section{Research method and data collection}

Research conducted through the PATHE program was undertaken with view to create a better insight and understanding of the way in which Pacific communities engage in higher education. More so, it aimed to further nuance an evolving socio-cultural lens on how Pacific communities define their own participation, whilst striving to highlight possible neo-colonial and neo-liberal challenges evident in tertiary education.

The survey data drawn upon below considers the perspectives of 120 respondents who are previous or current PATHE university students; describing their perspectives of challenges that Pacific peoples face in relation to higher education. These surveys were conducted across PATHE activities and events between 2014 and 2015. Participants were asked to enter their feedback anonymously via an online survey distributed by Survey Monkey, with 9 specific questions profiling their involvement in the PATHE program. Various questions within the survey had a Likert scale to assist participants to rate their response, with the option to also provide further feedback in a comments box. Other questions were open ended, with view to collate key themes evident from the researched cohort. From a cultural perspective, data was collected in the hope that key quotes would be gleaned, and further support underlying narratives that reflect practical implications of being at University, and the possible support 
needed to achieve completion. Therefore, certain quotes have been cited in longer form to maintain context and an in situ understanding.

Survey questions were developed with view to provide participants with an ability to meaningfully reflect and share open and honest feedback about being involved in a widening participation program that strives to encourage individual engagement within a tertiary setting; whilst imploring a broader, more objective understanding of their contribution to the collective including other students, family and wider community. More so, questions posed were designed to assist in both unpacking the value associated with operating a transition \& retention program like PATHE, underpinned by creating a more nuanced and overt message that cultural diversity and its difference can still shape the successful progression and completion of studies at University; rather than be assimilated into a tertiary education system and broader neo-colonial society.

The data collection period occurred between July 2014 - June 2015. Human Ethics clearance was sought and granted by Western Sydney University; approval number H10625.

\section{Key findings}

\section{Question 1: Participation in PATHE}

Figure 1 shows the scope and level of participation from PATHE university student respondents. Weekly meetings were the most popular activity of PATHE, where students are provided the opportunity to share and celebrate their successes individually (both personally and academically) whilst looking for solutions to the challenges they may encounter through a collective conversation with each other. Students may also develop a sense of voice from these interaction, finding a place amongst the group, wider university environs and beyond. 
This can provide further influence on the way in which students are encouraged to develop their level of agency in their studies, and other areas of wellbeing (Brännlund, Nordlander, \& Strandh, 2012).

Community events like Bring The Family to Uni strives to promote engagement with all members of the family and serves to bolster Pacific students' aspirations to enter and complete higher education, with an underlying philosophical understanding that if the parents of a child understand the significance of completing a tertiary qualification, it is more likely that they will encourage their child(ren) to carry their studies through to completion (Fischer, Barnes, \& Kilpatrick, 2017).

Figure 1: PATHE student involvement in PATHE activities

\begin{tabular}{|l|l|l|}
\hline ACTIVITY & NUMBER OF & PARTICIPATION RATE \\
\hline Weekly Meetings & 91 & $76 \%$ \\
\hline Bring Da Family 2 Uni & 65 & $54 \%$ \\
\hline Sporting Events & 54 & $43 \%$ \\
\hline Workshops in schools & 43 & $36 \%$ \\
\hline Social activities & 42 & $35 \%$ \\
\hline Annual awards & 34 & $28 \%$ \\
\hline Check it out campus tours & 32 & $27 \%$ \\
\hline Community events & 31 & $26 \%$ \\
\hline Ambassador duties & 15 & $13 \%$ \\
\hline
\end{tabular}




\section{Question 2: What factors have helped you get into University / College / TAFE?}

More than half the students surveyed stated that either parents and / or family members or their self-belief to be able to commence higher education is what brought them to be at their institution of study. Figure 2 outlines the factors that have contributed towards respondents' decision to enter higher education. Transport below refers to the students' ability to drive themselves to university, an important freedom that is not often acknowledged as a factor that influences attendance.

Figure 2 - What factors have helped you enter higher education?

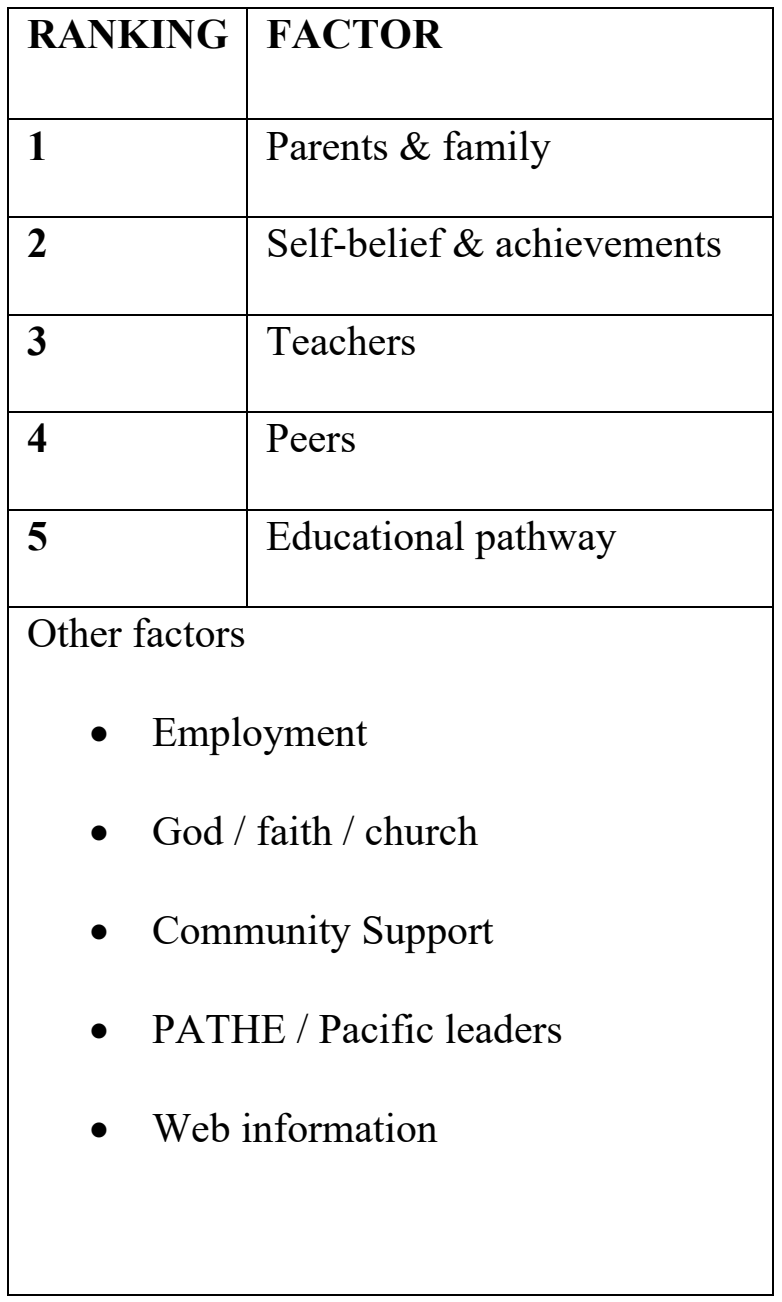


In their written responses to this question, participants highlighted the importance of family members, teachers and cultural liaison officers in urging self-belief to the point of admission into higher education. Consistently, peer support led to an internalisation of belief that attaining higher education was possible. There is also a strong recognition of God, faith and church inspiring self-confidence to pursue higher education.

When asked what factors helped them access higher education, the three following students stated:

The support of my husband and family...The love, care, and financial support from all of them. (Participant \#15)

My mother always instilled in me a strong respect for education. For me this meant there was no choice other than to study. (Participant \#55)

My support system was my number one factor for getting me into uni! My family is what made me get to where I am now. Also my hard work and study! I never thought there was a possibility of me getting into uni...I wish many Islanders realized it is not rocket science, anyone can get into uni if they wanted to with hard work and determination. (Participant \#67)

The support systems at home and within the institution of study, then, go a long way towards encouraging retention and completion of course. Although this appears as common sense, respondents have expressed the need for specifically Pacific support systems, where they feel understood, and culturally relevant speakers and leaders provide inspiration to pursue and complete their degrees. This notion supports the key idea that engagement in higher 
education should be more than induction and development alone, but rather a process of becoming where influences like family, friends and faith further reinforce underlying aspirations towards lifelong learning (Edwards \& Mackenzie, 2005).

When asked if they were the first in their family to enter higher education, $51.69 \%$ responded affirmatively, whereas only $8.47 \%$ were the first to enter TAFE study. $39.83 \%$ of respondents were not the first to enter university, while $13.56 \%$ were not the first to enter TAFE. Overall then, $60.16 \%$ of respondents were the first in family to attend further education and training post high school.

The vast majority of respondents $(80.67 \%)$ were, at the time of the survey, studying Bachelor's level courses. Others were completing their Masters (7.56\%) and Diploma (5.88\%), with a very small number completing $\mathrm{PhD}(0.84 \%)$, Certificates I through IV ( $0.84 \%$ respectively, with no Certificate II responses), Statements of Attainment $(0.84 \%)$ and University Foundation Courses (0.84\%). Of these students, 49.17\% came directly from school, $24.17 \%$ after studying TAFE, $18.33 \%$ as mature age students, $7.5 \%$ after studying an undergraduate degree at University, and $0.83 \%$ had to take a test prior to admission (with no further information provided of the nature of the test).

\section{Question 3: As a result of being involved in PATHE, I feel...}

Students were asked about various aspects of their interpersonal development, such as feeling an increased sense of support as a result of being part of the PATHE program, whether career goals had been reinforced, and feeling valued as a student as a result of participation. Figure 3 highlights the responses to this question. 
Figure 3: As a result of being in PATHE, I feel...

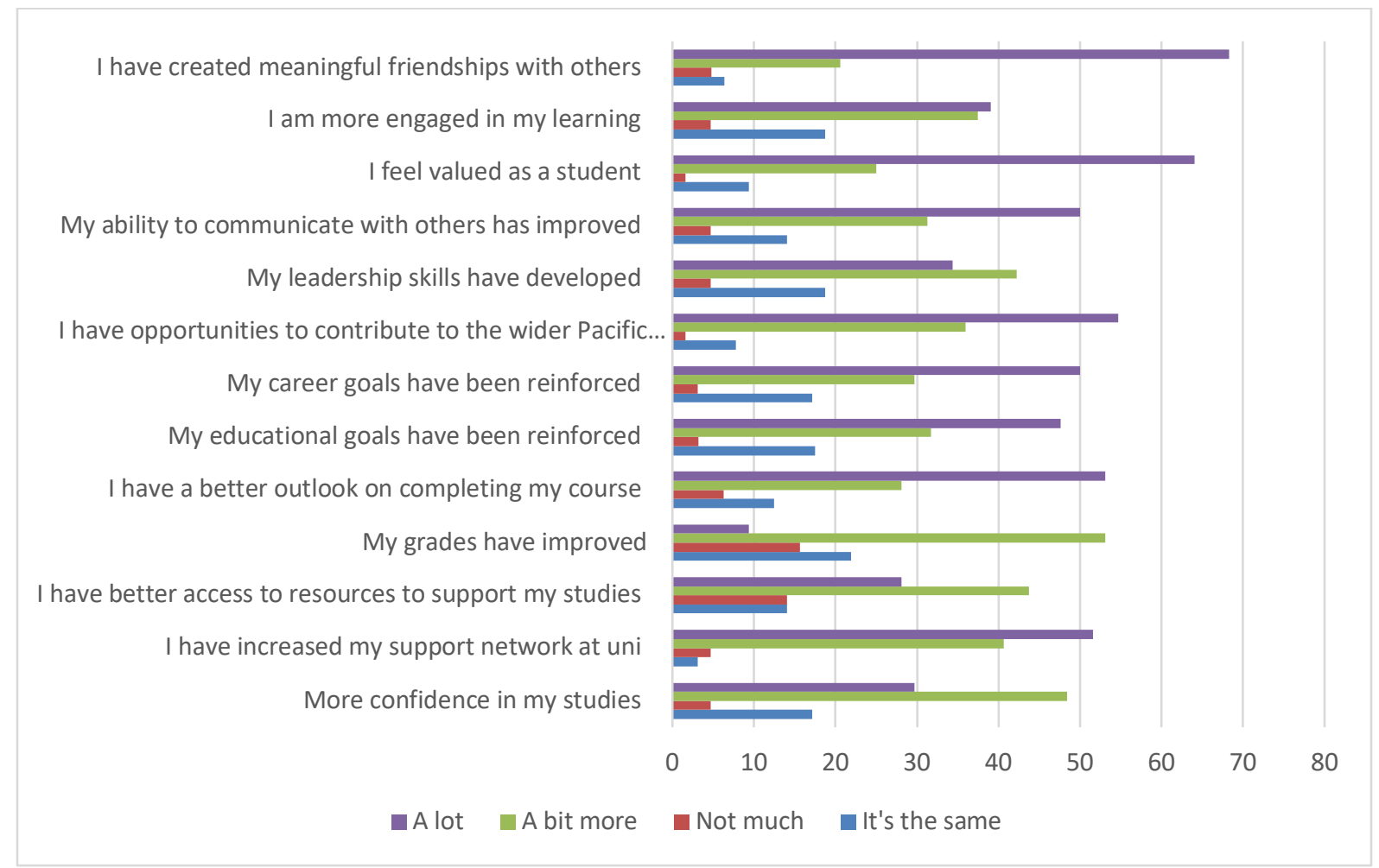

Participating in a retention support at University has improved students' academic performance, with $48.44 \%$ stating that they are a bit more confident, and $29.69 \%$ stating they are a lot more confident. Improvement in grades has been recognised a bit more by $53.13 \%$, and a lot more by $9.38 \%$. A marked shift in outlook towards completion has also been noted: $28.13 \%$ claiming a bit more and $53.13 \%$ a lot more. Educational goals have also been reinforced overall, with $31.75 \%$ improving a bit and $47.62 \%$ a lot. Consequently, career goals have been heightened, with $29.69 \%$ claiming a bit and $50 \%$ a lot. $37.50 \%$ stated that they feel a bit more engaged in their learning, while $39.05 \%$ stated they were a lot more engaged. Access to resources has also increased as a result of participation, either a little $(43.75 \%)$ or a $\operatorname{lot}(28.13 \%)$. 
Interpersonal skills were also noted as being improved as a result of participation in the program. $42.19 \%$ claimed that their leadership skills had improved a bit, with $34.38 \%$ improving a lot. Respondents' ability to communicate with others also improved $-31.25 \%$ stated a bit, and 50\% stated a lot. These are significant points to consider, as leadership and communication skills are vital soft skills that prepare students of any background and industry for professional practice, and increase their desirability in competitive employment.

The positive social support and bettering of self-esteem that results from engagement with other participants in the PATHE program has been highlighted as the most frequent responses. $40.63 \%$ stated that their social networks have increased a bit, with $51.56 \%$ stating a lot. $35.94 \%$ stated that they feel a bit of opportunity to contribute to the wider Pacific community, while $54.69 \%$ stated they had a lot of opportunity to do so. $25 \%$ stated they feel a bit more valued as a student as a result of participation in PATHE, while $64.06 \%$ stated they felt a lot more valued. The creation of meaningful friendships scored highest for positive responses, with $20.63 \%$ claiming this has happened a bit and $68.25 \%$ a lot.

The support offered via the PATHE program, then, is providing academic, social and professional support for these respondents. These services challenge the competitive neoliberal paradigm that pits university students against each other in the hope of creating a more entrepreneurial environment (Ashwin \& McLean, 2005). On the contrary, the collaborative approach to supporting others throughout tertiary education, which is perhaps a more culturally relevant mode of engagement for Pasifika students when compared to the unabashed individualism so promoted by Western neoliberalism, is more conducive to success for students in the program. That said, given that the highest responses were in the categories of social inclusion and feelings of value, it is possible that some students use the initiative as a social engagement tool rather than exploiting the academic development 
opportunities that are afforded them through the supportive efforts of the PATHE Project Officers.

\section{Question 4: Do you believe that PATHE is an important initiative?}

Participants were asked to give written responses to whether they thought initiatives like PATHE is important for Pacific people and if so why. From a total of 56 responses, the majority highlighted PATHE's ability to create a sense of togetherness and belonging (32\%) and support (34\%). Other areas that students reflected on included increased academic confidence and performance (18\%), encouraging personal aspirations (16\%), placing a higher value on education as a result of being involved (9\%) and fighting stereotypes (7\%). The remaining responses explored perceptions of personal value, cultural understanding, networking, ways of learning, environment and empowerment, totalling $2 \%$ each. Five of the most pertinent views are shared below:

Seeing a Pacific person who is [completing further studies] and telling you about it makes it more attainable. (Participant \#4)

I take it upon myself to use [PATHE Project Manager \& Academic] as my inspiration to further inspire to aspire. To motivate the now generation of Pacific youth to take advantage of our parents coming here from the islands so that we may do better than they did. So that we may have more than what they had. So that we can show the next generations it's normal for us Pacific people to have those important jobs in society. (Participant \#21) 
[PATHE] help[s] us as a people group and minority beyond our negative society enforced stereotypes, achieve more, break barriers and unlocking our true potential. (Participant \# 32)

I honestly would not of enjoyed my time at university if I did not attend PATHE, because I now know a lot more people like me, and I feel a great sense of belonging. I want other Pacific Islanders to feel the same way as well! (Participant \#34)

PATHE saved me from leaving Uni in my first semester. Meeting 3 PATHE members one afternoon when I was contemplating giving up made all the difference. Attending my first PATHE meeting was a great experience. I no longer felt alone or an outcast. Sad but true. (Participant \#50)

As discussed in the literature, the need to promote scope for those in the margins to be empowered and actively involved in utilising their own positions to navigate and negotiate how they choose to be perceived is evident here (Burke, 2013; Burke, Bennett, Burgess, Gray, \& Southgate, 2016). Rather than taking on the various labels and stereotypes already placed on Pacific young people and families, the PATHE program is providing scope to support a more strength-based approach and perspective to be forged.

\section{Question 5: My future goals}

Figure 4 reflects how participants felt about their future goals as a result of their participation in support provided by PATHE. 
Figure 4: My future goals $(n=106)$

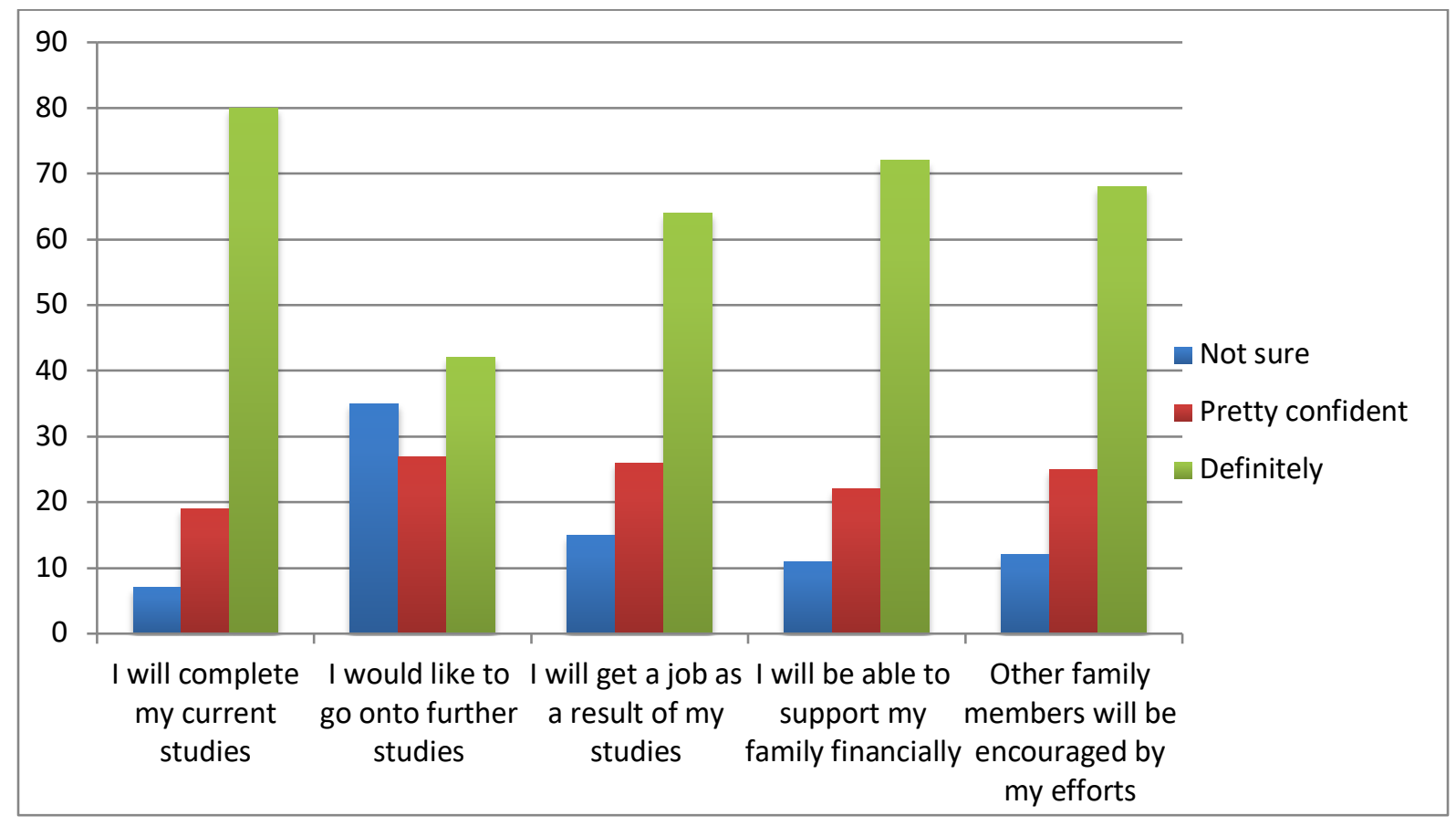

Rather than seeking only the individual benefits of higher education, the 106 responses to this question have highlighted how their tertiary qualifications improve the lives of those around them - in this case, their families. This collective focus once again challenges neoliberal ideologies on individual profits being one of the sole motivators for tertiary study and implies social mobility for the student and potentially those around them.

Taking all into account, one of the effective tools for retention for Pacific students may be the social and emotional support founded through a program aiming to understand the collectivist context of Pacific communities. Without this socially-based support, academic support is not holistic in addressing the needs of the entire person, which appears to have an enduring effect upon retention and support in light of the perspectives shared (Uehara, Chugen, \& Raatior, 2018). 
Question 6: What factors deter your ability to complete University / College / TAFE?

Paradoxically, family is the single largest inhibitor for respondents completing their qualifications, followed closely by monetary constraints and stress or other internal factors. Other factors are considered in Figure 5 below.

Figure 5: What factors deter your ability to complete University / College / TAFE?

\begin{tabular}{|c|c|}
\hline RANKING & FACTOR \\
\hline 1 & Family \\
\hline 2 & Work / money \\
\hline 3 & Stress / internal factors \\
\hline 4 & Friends / social \\
\hline 5 & Time management \\
\hline 6 & No support \\
\hline 7 & Inability to defer \\
\hline 8 & Workload / unfinished work \\
\hline 9 & Health issues \\
\hline 10 & Sport \\
\hline \multicolumn{2}{|c|}{ Other Factors } \\
\hline \multicolumn{2}{|c|}{ - Lack of resources } \\
\hline \multicolumn{2}{|c|}{ - Church / faith } \\
\hline \multicolumn{2}{|c|}{ - Children } \\
\hline - Distr & tions \\
\hline
\end{tabular}


Once again, students were asked to provide written responses to this question. The most pertinent four perspectives are shared below:

Not having someone to supervise and take care of my children while I have class will be a serious factor in preventing progress within my course. No access to welfare / Centrelink payments is another important factor. Not having moral support from family might also be a factor. (Participant \#41)

Family - my father died and my mother is old. Is she needs me, I might have to leave school and go back home. (Participant \#48)

Wanting to enter full time employment to support my goals and family, but I would never actually drop out to work full time. That would fulfil short term objectives rather than the long term vision I have for myself. (Participant \#86)

Friends at uni and sometimes Islanders who ask you to miss class or just are not motivated to study with you or even be at Uni. (Participant \#101)

It is significant to note that many Pacific students may have New Zealand citizenship and not necessarily Australian citizenship, which renders them unable to defer university fees, necessitating long work hours without access to social support services. Add to this the elongated processes for New Zealand citizens to become Australian citizens (longer than other migrants), proving difficult for New Zealand born and / or raised Pacific students in 
Australia to have the sense of financial support that many may take for granted. Although legislation is changing, albeit quite slowly, this has been an influential factor that keeps Pacific communities in the general population from undertaking study in Australia (Kearney \& Glen, 2017).

The time management required to balance the pressures of family expectations amongst other demands can often overwhelm Pasifika students who are enrolled in higher education; therefore, retention programs like need to offer a space where these stresses can be articulated, and encourage perseverance and time management strategies that take into account these cultural realities. Generally, universities may be reluctant to fund such programs on the basis that students should only abide by an existing process of engagement which is to accumulate knowledge alone, rather than creating spaces and new knowledges that in turn inform the Academy to sustainably engage and support such equity groups.

\section{Question 7: What do you see as the main benefits of completing University / College /}

\section{TAFE?}

As can be seen in Figure 6, various concepts were perceived as the benefits of completing higher education. As these were written responses, participants answers could address several areas. The overriding benefit for completing higher education for respondents was the selfinterest they had in the subjects being studied (85\%). The second most popular response was a desire to help those around them with meaningful work - altruism was desirable to $29 \%$ of participants. The benefits for family (19\%), money (15\%) and the value of education in its own right (14\%) were also highlighted, amongst other concepts shown below. 
Figure 6: What do you see as the main benefits of completing Higher Education?

\begin{tabular}{|c|c|}
\hline RANKING & BENEFIT \\
\hline 1 & Self interest \\
\hline 2 & Altruism / sharing \\
\hline 3 & Family \\
\hline 4 & Money \\
\hline 5 & Value of education \\
\hline \multicolumn{2}{|c|}{ Other benefits: } \\
\hline \multicolumn{2}{|c|}{ - Self-esteem / reputation } \\
\hline \multicolumn{2}{|c|}{ - Social benefits } \\
\hline \multicolumn{2}{|c|}{ - Love of work / field } \\
\hline \multicolumn{2}{|c|}{ - Alternative to sporting career } \\
\hline
\end{tabular}

One student summarised in their response the voice of many when they stated

The benefits are plenty. You['re] a good role model for the community, your education helps to break stereotypes, applying your knowledge to community assists others in hopefully realising their potential. My family respect me and I use my education to both benefit and influence family members. I feel I'm empowered to give back to my community by advocating and raising issues that may affect my people... My degree also gives me [peace] of mind - knowing that I have completed studies and I have a profession as opposed to a job...I feel the main benefits for me don't come from the potential money or status I will eventually earn but from how I've grown as a person. How my character and attitude have better developed and how this has positive effects on the people around me. (Participant \#59) 
The factors identified as benefits of completing a degree, particularly external motivators such as the ability to provide for one's family, reinforce a desire to keep at study and reach towards course completion, which are often shared by Pacific university students. The desire to also positively shape and create better opportunities beyond the margins, stereotypes and labels generally afforded within Western societies (Orupabo, 2018) where also at the core of such responses.

\section{Question 8: Do you also currently work in paid employment whilst studying?}

As is normal for many first in family university students, many respondents stated that they engage in either part-time or full-time employment while studying. Figure 7 shows the number of hours worked by students. There is a considerable amount of respondents $(15 \%)$ that are working up to 40 hours per week, which would place considerable strain on one's ability to complete studies to the best of one's ability. Present legislation that stops New Zealand citizens from being able to claim HECS or FEE HELP loans may be a cause for the need to work so many hours per week whilst studying. Obviously, other factors such as mortgages and family responsibilities would also come into play, but it would be worth conducting this same survey under changed legislation to see if this figure remained at this level. This could inhibit students' ability and desire to maintain study, and changing legislation around access to HECS or FEE HELP loans would greatly increase the likelihood of Pacific student retention and success (Kearney \& Glen, 2017). 
Figure 7: Do you also work whilst studying?

\begin{tabular}{|l|l|}
\hline Weekly hours worked & \% of participants $(\mathbf{n}=\mathbf{1 2 0})$ \\
\hline None & $40 \%$ \\
\hline Up to 10 hours & $18 \%$ \\
\hline Up to 20 hours & $19 \%$ \\
\hline Up to 30 hours & $8 \%$ \\
\hline Up to 40 hours & $15 \%$ \\
\hline
\end{tabular}

The need to work may also reflect a growing trend within Universities that have a large cohort of first in family, and those within various equity groups to still be proactively engaged in paid employment to keep up with other demands, as opposed to being fully immersed in study and other scholarly outputs in conjunction with chosen course (O'Shea, 2016b). Such divided focus may deter ability to critically acquire and produce knowledge at this level of education, and rather participate as consumers and passive learners. At the same time, the need for Pacific students to undertake courses where there is a clear vocational outcome and better articulation of employment is also evident. In essence, this may deter certain opportunities to undertake degrees of 'higher order thinking' or of a critical nature, which may decrease possible aspirations towards higher degree research through Masters \& $\mathrm{PhD}$ level programs.

\section{Question 9: How do you manage the additional commitments while studying?}

Participants highlighted the many other commitments that are a part of their lives. Once again, family commitments appeared difficult to juggle alongside higher education, with $51.96 \%$ 
stating that this was somewhat difficult to manage and $14.71 \%$ stating this was difficult to manage. Social commitments were also onerous $-42.72 \%$ stated they were somewhat hard to manage, while $18.45 \%$ stated this was difficult to manage - the highest percentile in this category. Health commitments were similarly high in the 'somewhat hard to manage' category. These statistics are visualised in Figure 8.

Figure 8: How do you manage additional commitments while studying? (n=120)

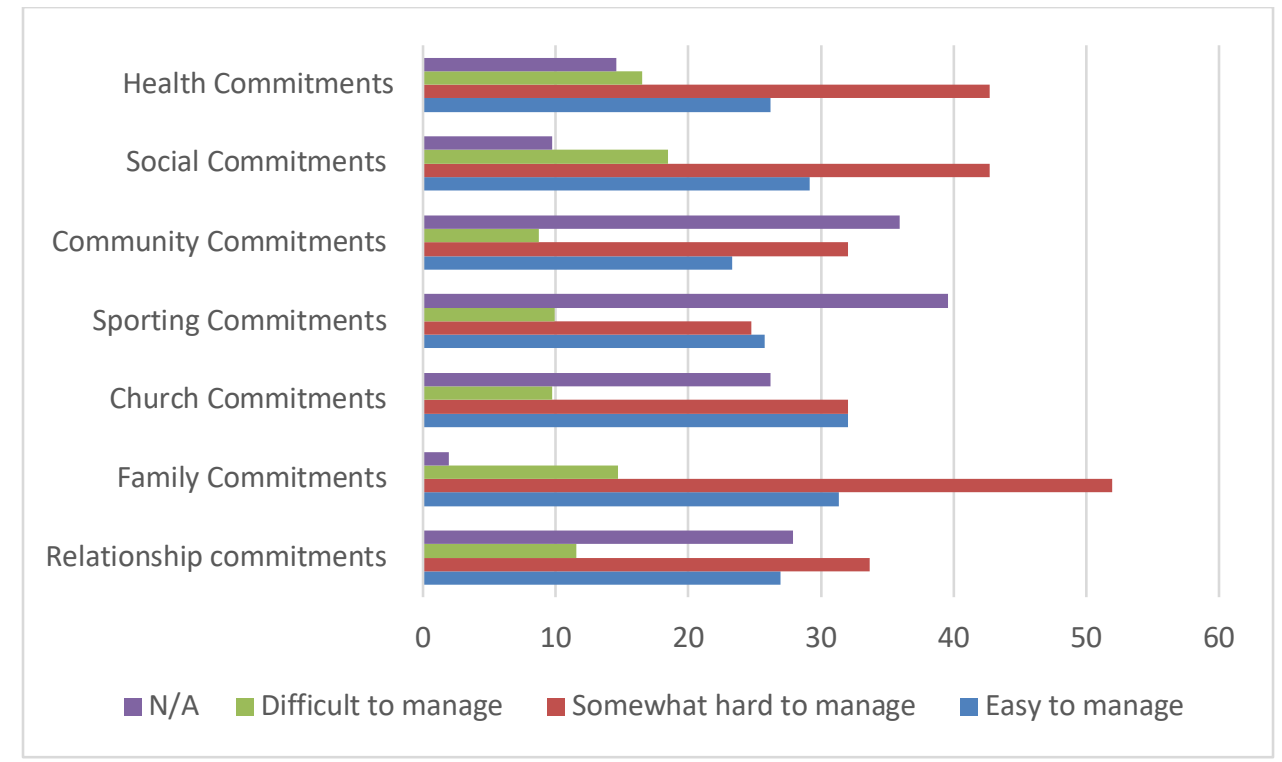

If Universities are going to be institutions that are less market driven, and more led by an ambition to serve industry and the wider community, then they need to also be a place where the students' reality inform the way in which they operate and engage. 


\section{Conclusion}

Through feedback given by participants in and across the research, it has provided further evidence on the need to create University based programs that go beyond study skills and academic workshops. Students who are not traditionally familiar with a tertiary environment and are from collectivist cultures may benefit most from tailored programs that understand such variables and factors, whilst also exploring benefits and solutions that counteract disengagement. Rather than relegate such cultural strengths as being less favoured within a neo-liberal institution, it may be more suitable to include, and create spaces where people feel valued for their diversity and difference. Successful course completion may result, which in turn provides a win-win outcome for the tertiary provider, for the student, and the Pacific community who now benefits from an additional member having enhanced skills and attributes to support cultural capital and mobility. At the same time, the tertiary system also benefits from being challenged to respond in a collaborative manner, learning to reshape and re-shift its policies and practices away from being solely market driven and focussed.

Opportunities to provide students from equity groups the ability to create their own space and place can also benefit educational engagement and retention more broadly. As evident with many of the participants, their goal was to be a great example to others in the Pacific diaspora, and possibly prove to self (and their naysayers) that Pacific people can achieve in higher education. Such discourse then provides scope for the marginalised to be considered as possible contributors beyond the margins, and to see systems potentially changed to be more inclusive. This includes the need to reconsider the way in which University's position their own epistemological and pedagogical approach to tertiary education, and the possible need to move towards structures that challenge the tenants of western scholarly and academic rigour. That is, by having more ethnically diverse people come through Universities, even as academics themselves, may transform the way in which Australian tertiary providers see their 
role as not just moulding intellect alone, but rather creating critical consumers and producers of new knowledge nuanced and informed by cultural diversity and its differences. In turn, such diverse knowledge production will assist in the ongoing development and relevance of lifelong education within a cosmopolitan reality of being part of a complex global community characterised by an array of perspectives, not just one. 


\section{References}

Ashwin, P., \& McLean, M. (2005). Towards a reconciliation of the "approaches to learning" and "critical pedagogy" perspectives in higher education through a focus on academic engagement. Improving Student Learning: Diversity and Inclusivity, 12, 377-389.

Bibbings, L. S. (2006). Widening participation and higher education. Journal of Law and Society, 33(1), 74-91. https://doi.org/10.1111/j.1467-6478.2006.00348.x

Bowles, A., Fisher, R., McPhail, R., Rosenstreich, D., \& Dobson, A. (2014). Staying the distance: students' perceptions of enablers of transition to higher education. Journal of the Higher Education Research and Development Society of Australasia, 33(2), 212-225. https://doi.org/10.1080/07294360.2013.832157

Brännlund, A., Nordlander, E., \& Strandh, M. (2012). Higher education and self-governance: the effects of higher education and field of study on voice and agency in Sweden. International Journal of Lifelong Education, 31(6), 817-834. https://doi.org/10.1080/02601370.2012.733891

Burke, P. J. (2013). The right to higher education: beyond widening participation. International Studies in Sociology of Education, 23(2). https://doi.org/10.1080/14748460.2013.802891

Burke, P. J., Bennett, A., Burgess, C., Gray, K., \& Southgate, E. (2016). Belonging and Equity in Higher Education: Developing inclusive approaches. Newcastle. Retrieved from https://www.newcastle.edu.au/_ data/assets/pdf_file/0011/243992/CAPABILITYONLINE.pdf

Curtin University. (2013). Access and Participation in Higher Education. Perth. Retrieved from http://www.ncsehe.edu.au/wp-content/uploads/2013/11/NCSEHE-Access-andParticipation-in-Higher-Education-2013.pdf

Deleuze, G. (1988). Spinoza: Practical Philosophy. San Francisco: City Lights Books.

Edwards, A., \& Mackenzie, L. (2005). Steps towards participation: the social support of learning trajectories. International Journal of Lifelong Education, 24(4), 287-302. https://doi.org/10.1080/02601370500169178

Fa'avale, A., O'Brien, G., Green, A., \& McLaughlin, J. (2016). "May the coconut tree bear much fruit" - QUT's 'niu' framework for outreach and retention with Maori and Pasifika students. In Students Transitions Achievement Retention and Success Conference (pp. 2-5). Perth.

Fischer, S., Barnes, R. K., \& Kilpatrick, S. (2017). Equipping parents to support their children's higher education aspirations: a design and evaluation tool. Educational Review, 1-20. https://doi.org/10.1080/00131911.2017.1379472

Freire, P. (1996). Pedagogy of the oppressed (Revised Edition). (M. B. Ramos, Ed.). London: Penguin Books.

Freire, P., \& Macedo, D. P. (1995). A dialogue: Culture, language, and race. Harvard Educational Review. https://doi.org/10.17763/haer.65.3.12g1923330p1xhj8 
Gale, T., \& Parker, S. (2012). Navigating change: a typology of student transition in higher education. Studies in Higher Education, 39(5), 734-753.

https://doi.org/10.1080/03075079.2012.721351

Gatens, M., \& Lloyd, G. (1999). Collective Imaginings: Spinoza, Past and Present. London: Routledge.

Giroux, H. A. (2002). Neoliberalism, corporate culture and the promise of higher education: The university as a demographic public sphere. Harvard Educational Review, 72(4), 424-463.

Giroux, H. A. (2010). Bare Pedagogy and the Scourge of Neoliberalism: Rethinking Higher Education as a Democratic Public Sphere. The Educational Forum, 74(3), 184-196. https://doi.org/10.1080/00131725.2010.483897

Kearney, J., \& Glen, M. (2017). The effects of citizenship and ethnicity on the education pathways of Pacific youth in Australia. Education, Citizenship and Social Justice, 12(3), 277-289. https://doi.org/10.1177/1746197916684644

O'Shea, S. (2016a). Avoiding the manufacture of 'sameness': first-in-family students, cultural capital and the higher education environment. Higher Education, 72(1), 59-78. https://doi.org/10.1007/s10734-015-9938-y

O'Shea, S. (2016b). First-in-family learners and higher education : Negotiating the ' silences ' of university transition and participation. HERDSA Review of Higher Education, 3, 1-23.

Olssen, M., \& Peters, M. A. (2005). Neoliberalism, higher education and the knowledge economy: from the free market to knowledge capitalism. Journal of Education Policy, 20(3), 313-345. https://doi.org/10.1080/02680930500108718

Orupabo, J. (2018). Cultural stereotypes and professional self-socialisation in the transition from education to work. Journal of Education and Work, 31(3), 234-246. https://doi.org/10.1080/13639080.2018.1459513

Peacock, D. R. (2014). Practising equity: the activation and appropriation of student equity policy in Queensland higher education. The University of Queensland. https://doi.org/10.14264/uq1.2014.275

Pitton, V. (2007). Disentangling Chile's authoritarian neoliberalism and its effects: the downfall of public higher education and its implications for equitable access. Critical Studies in Education, 48(2), 249-267. https://doi.org/10.1080/17508480701494267

Quinn, J. (2010). Rethinking 'failed transitions' to higher education. In K. Ecclestone, G. Biesta, \& M. Hughes (Eds.), Transitions and learning through the lifecourse (pp. 118129). London: Routledge.

Ravulo, J. (2015). Pacific Communities in Australia. Sydney. Retrieved from https://www.westernsydney.edu.au/_data/assets/pdf_file/0006/923361/SSP5680_Pacifi c_Communities_in_Aust_FA_LR.pdf

Ravulo, J. (2016). Pacific Youth Offending within an Australian Context. Youth Justice, 16(1). https://doi.org/10.1177/1473225415584983

Redmond, P. (2006). Outcasts on the inside: Graduates, employability and widening 
participation. Tertiary Education and Management, 12(2), 119-135.

https://doi.org/10.1007/s11233-006-0002-4

Reed, R., King, A., \& Whiteford, G. (2015). Re-Conceptualising Sustainable Widening Participation: Evaluation, Collaboration and Evolution. Higher Education Research and Development, 34(2), 383-396. https://doi.org/10.1080/07294360.2014.956692

Sellar, S., \& Storan, J. (2013). "There was something about aspiration": Widening participation policy affects in England and Australia. Journal of Adult \& Continuing Education, 19(2), 45-65. https://doi.org/10.7227/JACE.19.2.4

Thomas, L. (2002). Student retention in higher education: the role of institutional habitus. Journal of Education Policy, 17(4), 423-442. https://doi.org/10.1080/02680930210140257

Tualaulelei, E., \& Kavanagh, M. (2015). University-Community Engagement: Mentoring in the Pasifika Space. The Australasian Journal of University-Community Engagement, 10(1), 87-106.

Uehara, D. L., Chugen, J., \& Raatior, V. S. (2018). Perceptions of Pacific Islander students in higher education. Journal of Diversity in Higher Education, 11(2), 182-191.

https://doi.org/10.1037/dhe0000057 